\title{
Electronic business mode analysis and Prospect
}

\author{
Weng Dongdong \\ Quanzhou Normal University , \\ Fujian Quanzhou ,China \\ E-mail:weng28911985@163.com
}

\author{
Wang Xiaofang \\ Liming Vocational University, \\ Fujian ,Quanzhou ,China \\ E-mail:weng28911985@163.com
}

\begin{abstract}
In the Internet age, e-commerce has been an unprecedented development, at the same time it has changed our traditional business processes, and produce many new business models, e-business models in addition to the classic B2B, B2C, C2C e-commerce model, the also there were many new successful e-commerce operation. In this paper, the current main mode of the advantages and disadvantages of e-commerce perspective, and how to blend blend of B2B, B2C and C2C their respective strengths to overcome their shortcomings and put forward new models and innovative e-commerce to improve and perfect the new e-business models to be solved the problem.
\end{abstract}

Keywords-component; e-commerce model; analysis innovation; B2C2C

\section{I.BACKGROUND}

Engage in e-commerce business in the country the number of sites, the only difference lies in the sale of different products, basic e-commerce mode is nothing more than the Alibaba B2B model, Jingdong, Dangdang, excellent as the representative of B2C mode , to Taobao C2C mode. You I only do in the e-commerce industry, you have my priorities, you gifted me strong competition in order to realize the difference for themselves in the competitive fight for time and customer. 0 Therefore, on the basis of this B2B, B2C, C2C mode innovation to overcome the defects of existing models, inadequate, there have been new concepts have been proposed, the new model is applied, these new concepts, new ideas, new modes of operation the emergence.of further promoting the innovation and development of e-commerce .

\section{II.INNOVATION AND EXPLORATION OF NEW E-COMMERCE MODE}

e-commerce a new model - B2C2C mode

Innovation and development of the Internet, e-commerce and consumer capital designed to draw the essence of the theory, combined with traditional marketing experience with Internet online shopping platform experience in building, operating the Internet in the field of e-commerce "B2C" and "C2C" shop creative upgrade mode, create $\mathrm{B} 2 \mathrm{C} 2 \mathrm{C}$ concept shop platform [7].B2C2C Business To Channel To Customers Chinese translation: enterprise --- channels --- customers to provide enterprises with a network of direct sales channels, the shop boss as consumers purchase from the platform, the customer (end consumer) purchase by enterprises Direct shipments. For the shop, there is no inventory to sell goods after the payment, the risk is almost zero. For supply manufacturers, which is an online direct marketing platform, eliminating the need for cumbersome traditional supply channels. One does not need to bear the the channel cost but with consumers direct docking platform, the platform site to find the potential risk-sharing, the dream of all businesses are B2C2C charm unstoppable.

\section{III.B2C2C MODE ADVANTAGES PERSPECTIVE}

B2C2C mode is efficient integration of the advantages of B2B and $\mathrm{C} 2 \mathrm{C}$ mode, beyond the original two modes, a new type of e-commerce mode. It fully blend their respective advantages $\mathrm{B} 2 \mathrm{C}$ and $\mathrm{C} 2 \mathrm{C}$ mode, to make up for their shortcomings. Businesses after the product in the presence $\mathrm{B} 2 \mathrm{C} 2 \mathrm{C}$ mall, not with the specified online sales of specialized personnel, products only need to show in the mall can be hundreds of thousands of members and shopkeepers in the mall can become a merchant network promotion window channels, the equivalent of the merchants is equivalent to have tens of thousands of distributors terminal.On the other hand, the platform is responsible for centralized recruited into suppliers and national toll-free call center service member or the owner only needs free registration online shop you can self-consumption or distribution. The innovation of this mode is that it continues B2C model platform supply stability, supply advantage of the many aspects of quality assurance, security, and integrity the same unified negotiate B2C2C Mall Merchants ensure the quality and stability of the supply.Mall to the protection of genuine, fake a lose three, the complaint rate exceeded the shelves to protect the legitimate rights and interests of consumers; C2C mode platform individual consumers and to carry forward the force consumers into sales channels, advertising providers reach to promote their products and brand by consumers own interpersonal circle [8]. The introduction of the concept of the production and consumption of "consumers went back to the front-end from the end of the chain of production and consumption, to become" flowers make the production of consumer access to the actual income.Consumers can obtain higher loyalty, but also can make high-quality goods and rapid promotion. And $\mathrm{B} 2 \mathrm{C} 2 \mathrm{C}$ mode to solve the traditional Shop owner need to purchase, delivery, after-sales, customer service, and a series of problems, B2C2C mode the shopkeeper only need to focus on the promotion and sale of their own shops, the other by the mall harmonization process. So can greatly improve the 
efficiency of the transaction, and easily achieve zero risk, easy venture, worry-free operation.

B2C2C mode for C2C mode improved the involvement of third-party logistics platform to solve a series of problems of traditional shop own shipping, logistics by platform unified management, negotiations thus reducing out a large quantity of the point, easy and logistics companies logistics costs, or platform can rely on their own to build a logistics system. Cargo distribution services can also be provided directly by the manufacturer enterprise logistics problems plagued; platform for unified solve the problem of the supply network operators are $\mathrm{B} 2 \mathrm{C} 2 \mathrm{C}$ platform to platform as the basis.After businessmen stationed B2C2C Platform does not need to specify the personnel to make the sale, the product simply on display on the platform, so there is no inventory problems, but also to ensure that a small part of the funds network operators [9]. B2C2C platform give consumers the double guarantee more confidence: trust the platform itself, and another from the product quality, brand trust. C2C mode because it is a transaction between the individual and the individual transactions between buyers and sellers often do not have security, there is a big problem of the goods not meeting board, shoddy, fake, defective the B2C2C mode well resolved, strict control supply, severely punish the false, deceptive, network operators, in order to ensure the rights of consumers.

The B2C2C mode of information integration based on the network to provide businesses with direct sales channels, finished now between supply and demand "shortest path" and "fastest" by B2C2C platform manufacturers can immediately understand the needs of end customers can timely adjust their product mix to meet consumer demand; meet their individual needs and can be based on the needs of the end customer. This way to achieve an extension of the manufacturers in the supply chain, as well as the customer into the supply chain. Specifically, by the vendor's point of view, B2C2C new mode of e-commerce, Extremely effective promotional channels can be provided for them, can also reduce the cost of sales for suppliers to expand sales, provides a new method; from the consumer's point of view, B2C2C e-commerce platform allows them to buy more convenient their satisfaction with the product, experience the joy of online shopping, and enhance confidence in online shopping; from the point of view of employment by, B2C2C e-business models can enrich the supply channels, and easy to operate, and the logistics of goods supplied by the manufacturer directly, no plagued with logistical issues, B2C2C platform to stay focused on the construction of their own website, and strive to provide more services to more own characteristics, to attract a wide range of consumers [10].From the point of view of the e-commerce industry, the emergence of a new model, the current situation and the plight of a breakthrough in the industry. B2C2C mode to reduce the distribution channels in the low-carbon concept and efficient commodity experience, reliability, and the formation of a benign trends make online shopping, can better promote e-commerce, and further development. The ultimate purpose of a business is to maximize customer value B2C2C mode after the expansion of the supply chain, enterprises and downstream are able to operate more effectively, and at the same time, the entire system can also be set up and maintain.

\section{IV.REQUIRES B2C2C PLATFORM HIGH ABILITY TO INTEGRATE}

E-commerce enterprises need on B2C2C suppliers integrated management therefore demanding B2C2C platform technology, at the same time, the site also must provide a great value in terms of customer service, or difficult for customers to gather. And a huge customer base mode operation B2C2C basic conditions . Coupled with the complex logistics system platform requirements have to improve further.As an emerging e-commerce model, B2C2C platform to improve conversion rates, the need to strengthen the platform for building, strengthening the center of gravity of the platform in two aspects: one is the basis of service, value-added services. So-called basic service that is able to provide a good shopping experience for the customer, such as the growing rich category of goods, so that consumers be able to achieve one-stop shopping.

platform to strengthen the construction of multiple channels to attract popularity, to increase awareness

The emerging B2C2C e-commerce platform, a not well-known, and second, not popularity, consumers Third, we must change the concept of the need to integrate various resources to attract popularity, such as advertising, news sites, communities, promotion. In order to increase the flow of people use most of the way is advertising, online advertising, low-cost, closer to the target audience favored by many e-commerce platform, open various portals, vertical portals, e-commerce platform advertising has become the main character.

improve service levels and achieve win-win situation

If price is the most direct actuation consumers purchased factors, superior service is the key to repeat purchase. From the quality of goods, B2C and B2C2C mode there is no difference, the focus will therefore compete on price and service. To global B2C giant Amazon service is the best achievement of its e-commerce Albert weights only continue to improve service levels, in order to allow consumers to become loyal customers.

strengthen legislation to improve e-commerce legal system

E-commerce as a modern science and technology, the rapid development of new trade closely linked, presented unprecedented challenges to existing laws. E-commerce legal system plays a huge role in the normal functioning of the e-commerce activities, a mature legal system urgently improve. But the special e-commerce transactions, the formulation of related laws must be followed by the development of e-commerce trends. 


\section{V.CONCLUSION}

The e-commerce model is the core of the Internet business survival and development, with the e-commerce hot whirlwind scratch, a growing number of beach-goers, persistent Nuggets in the field of electronic commerce. The essence of e-commerce model is summed up in the "first use innovative model to attract users. Then quality service to retain customers.An innovative e-commerce model, is bound to attract the attention of Internet users, resulting in enormous profits. The analysis of e-business models, in order to better carry out innovative e-business models to promote the development of e-commerce enterprises . What are the basic mode of e-commerce, these models have advantages, disadvantages? How basic e-commerce model based on innovation, to create a new e-business models suitable for the enterprise's own special circumstances? How e-business models and strategies to continue to be successful? These are studies of e-business models need to pay attention to the problem, only deal with these problems, in order to obtain the e-commerce model innovation.

\section{ACKNOWLEDGEMENT}

This research was supported by the funds from:Foundation item1:Fujian Social Science Planning Project "District trade structure and economic growth---based on economic data research of western coast of Taiwan Straits", Project Number: 2012B134.Foundation item 2: Fujian university key project of the service for western coast of Taiwan Straits "Regional economic development research of Southern area of Fujian”, Project Number:B054. Foundation item 3:Construction Funas of Master Degree Awarded Unit of Quanzhou Normal University;Foundation item 4:Fujian university key project construction service routines "The port logistics information platform construction,Haqixi prefecture”,Project Number:A103.

\section{REFERENCES}

[1] LuoXinFang, “B2B e-commerce model” ,Agriculture Network letter, August, 2008

[2] ZhaoXiaohong, B2B: the main mode of e-commerce ,Southwest University for Nationalities · Philosophy and Social Sciences, 2010

[3] YaoLizi, Business commerce B2C model innovation strategy ,Era 12, 2008

[4] Lin feng, B2C2C: mess things up on new meaning in the new economy, July 2010

[5] Wang Sha, "Talking about e-commerce C2C exist and countermeasures”, E-commerce in China, October 2010

[6] ZhouTang, China's e-commerce development trend of ,Shantou Vocational and Technical College, 2010

[7] LiuXinhua, "Febay International to create a shop 3G era ", Economic Weekly, 40, 2009 